The International Society for Neuroimmunomodulation (ISNIM) comprises scientists involved in interdisciplinary research in molecular and cellular aspects of neurobiology, neuroendocrinology, immunology, hematology, oncology and the behavioral sciences. The Organizing Committee hopes that this conference will stimulate the most rigorous and sophisticated interdisciplinary research spanning the fields of neuroscience, immunology and hematology as well as the clinical disciplines of oncology, psychiatry, rheumatic diseases and endocrinology.

\title{
Fourth International Congress International Society for Neuroimmunomodulation
}

\author{
Lugano, Switzerland, September 29 - October 2, 1999
}

The focus of this meeting will be upon basic and clinical research in neuroimmunomodulation. Subject matter will include: relevance of circadian endocrine oscillators in immune responses with emphasis on the role of melatonin; neuroimmunomodulation perspectives in oncology; neural and neuroendocrine regulation of hematopoiesis; cytokines which affect the nervous system; thymic function and neuroendocrine interactions; the autonomic nervous system; catecholamines; neuropeptides; sex and pituitary hormones; inflammatory diseases; neuroimmunomodulation mechanisms in bacterial and viral diseases (including AIDS); human behavior; stress and the immune system.

\author{
For information contact: \\ Georges J.M. Maestroni, PhD or Ario Conti, PhD \\ Center for Experimental Pathology \\ Istituto Cantonale di Patologia \\ PO Box \\ CH-6601 Locarno 1 (Switzerland) \\ Tel. +4191756 26 71-72 \\ Fax +41917562690 \\ E-Mail ISNIM99@luganet.ch
}

KARGER ๑1998 S. Karger AG, Basel 